\title{
Influence of Far Eastern Culture on Russian Cinema of the First Half of the Twentieth Century
}

\author{
Rustem Mukhametzyanov \\ Kazan (Volga Region) Federal University, Russian Federation \\ Email: rustemr@mail.ru
}

\section{Doi:10.5901/mjss.2015.v6n3s2p195}

\begin{abstract}
The article examines the influence of oriental civilization on the formation of a new European culture at the example of S. Eisenstein's work. Eisenstein's interpretation of Far Eastern aesthetics as well as the use of the principles of hieroglyphics in the development of a now common author's method of film editing are being analysed here. Such a dialogical relationship of the Far Eastern culture with the Russian (European) one is an example of how human perception of the East by a westernised person becomes a fertile ground for creativity and formation of a new image of culture.
\end{abstract}

Keywords: dialogue of cultures, East - West, Chinese and Japanese cultures, Kabuki theatre, hieroglyph, film editing, sound editing, Chan Buddhism, synthesis of arts

\section{Introduction}

The crisis of European culture of the $19^{\text {th }}-20^{\text {th }}$ centuries and the search for a way out resulted in the European creative elite turning not only to the origins of European art but the traditions of the East too. It was the synthesis of new and wellforgotten old that a new Western European culture was formed on in the early $20^{\text {th }}$ century.

Several reasons may be pointed out to explain why European intelligentsia drew their attention to oriental countries. Firstly, this, as rightly observed by N. Berdyaev, was World War I which led to 'the end of Europe as a monopolist of culture, a self-contained province of the globe pretending to be the universe. It brought the East and the West into such a close contact history has not known yet' (Berdyaev, 1990), (Roshwald \& Stites, 2002). Secondly, under the influence of the technology revolution of the $19^{\text {th }}$ century the European worldview changed while the methods of its artistic reflection remained unchanged. Thus, turning to the oriental culture was associated primarily with the search for new methods and forms of creative reflection of reality.

A considerably new stage in the interaction of the cultures of the East and West began in the second half of the $19^{\text {th }}$ century. The desire of European artists to understand the creative principle of oriental masters was reflected in the works of the Impressionists (Breuer, K., 2010). For example, Matisse was convinced that 'there was discovered the main aesthetic pattern of creating an artistic image in the East' (Zavadskaja, 1970). But the most outstanding results of the influence of oriental forms and methods on the creative tradition of the West emerged only in the first half of the $20^{\text {th }}$ century. Since then a deeper and larger in scale interaction of the cultural forms of the East and West began.

The Europeans' turning to the oriental culture was initiated by the internal crisis of the Western European civilization. It is a conscious interaction of cultures. The question of the interaction of diverse national cultures, contacts in arts is the part of a generic issue of relations between nationalities that have different views on the world, the role and place of a human being in it, influenced by the economic development and government system.

It is also the issue of the respect for "foreign" culture, its perception or negation that are connected with the features of national identity, the spiritual climate of a certain period. This is a special kind of relations and contacts that is established between cultures, as well as the process of mutual influences and changes caused by these contacts. The fact that at least one of the cultures experiences a change in the cultural field in the process of intercultural dialogue is of crucial importance.

The changes that occurred in the European culture gave a fresh impetus to its development. But here arises the question of how these changes happen in the culture. In this respect, it seems necessary to analyse the role of personality in the process of cultural interaction. Selecting S.M. Eisenstein for this analysis is not accidental. He began his artistic career as a director in a Moscow theatre in the early 20s. It is natural that he turned to the traditions of the oriental theatre, as he had studied the Japanese language and the Japanese culture earlier, and was a theatre director 
and later became a filmmaker familiar with Mei Lan Fang and the Kabuki theatre. We believe that thanks to S.M. Eisenstein we may observe how a "foreign" cultural experience is transformed into the "own" one.

\section{Literature Review}

The studies of the interaction of cultures began long ago which took on a particular importance at the end of the $19^{\text {th }}$ century when a single diverse polyphonic space was formed on against the backdrop of the European cultural crisis. On the other hand, such cultural space creates difficulties for researchers as the problem is interdisciplinary. At the beginning of the $20^{\text {th }}$ century there appeared the works of M. Buber, F. Gogarten, F. Rosenzweig, A. Rosenstock-Huessy, H. Cohen, F. Ebner.

Further, the problems of intercultural dialogue have been discussed in sociolinguistics (L. Szczerba, L. Yakubinsky), literary and philosophical hermeneutics (H. Gadamer), phenomenology (H. Husserl, M. Mamardashvili), fundamental ontology (M. Heidegger), theory of literature and semiotics (A. Averincev, M. Bakhtin, M. Lakshin, Yu. Lotman), fundamentals of communication (A. Mole, V. Borev). The works devoted to the interaction of cultures include K. Levi-Strauss, G. Hershkovets, S. Artanovsky, S. Arutyunov, B. Yerasov, L. Ionin, N. Ikonnikova and others.

It would be right to assume that the problem of the interaction of cultures has been examined in depth. Nevertheless, Eisenstein's works have been mainly analyzed in connection with his art criticism. There is almost no research of his works devoted to the interaction of cultures and common cultural and historical background that requires comprehensive analysis.

\section{Research Methodology}

Intercultural dialogue is understood as the process of the interaction and integrity of diverse cultures in diachronic and synchronic perspectives.

The interaction of cultures actually happens on different levels. On the "vertical" level the dialogue of cultures is presented from past through present to future. On the "horizontal" level we consider the interaction of cultures that take place in the same time period. We are interested in the second one, when "living" cultures participate in the dialogue, exchange their experiences and model a new cultural element.

There are various views on the possibility of cultural and historical interaction itself that may be represented in the following way:

- Spengler denies the possibility of intercultural dialogue, calling it a "chimera" (Spengler, 1993);

- Danilevsky mostly denies intercultural dialogue (due to the negative impact of Peter's reforms on Russia), but he admits the possibility sometimes the need for certain intercultural contacts (Danilevsky, 1991);

- Toynbee points out that dialogue is a prerequisite for the development of a civilization and develops his concept of "contacts of civilizations". In his book "Study of History" Toynbee suggests to consider dialogue as a system of relations "Challenge - Response" between civilizations (contacts of cultural worlds) (Toynbee, 1991).

Modern researchers offer similar interpretations of cultural interaction. But they all agree that any culture cannot exist in a confined space; even the negation of "foreign" culture suggests its comparison with "own" culture, which affects the spiritual life. Any comparison is characterized by the relationship between "own" and "foreign" cultures, which helps define the boundaries of "own" culture. Thus, "foreign" culture enters to some part the perceiving consciousness as "ownbeing". It is not a complete assimilation; it is the transformation of "foreign" culture into unique "own". In any case, "foreign" culture remains different and exists not as "own different". The processes of realizing "own" and "foreign" cultures are merged together, but not reducible to each other.

\section{Main Part}

\subsection{Oriental Theatre}

In the first decades of the $20^{\text {th }}$ century performance venues were the places of the most active interaction. It should be noted that the European public was mainly getting acquainted with the theatrical tradition of the Far East (China and Japan) then. In 1928, Kabuki theatre was touring in Russia (Seton, 1952). This event was a milestone for the Russian theatre audience (especially for the intelligentsia) who were not familiar with the oriental theatre and its traditions. Actors and art lovers were amazed by the unique Japanese theatre which was completely different from the Russian one. 
At that time the European theatre was going through a difficult period of reorientation which was connected with the general cultural crisis of the turn of the centuries as well as with the fact that the new theatre director was looking for new forms and methods of expression. V. Meyerhold, one of the founders of the new theory of theatrical art in Russia, believed that the theatre needed eurhythmics rather than dialogues with the former dominating over the verbal part. An ideal play is the one that can be acted as pantomime without words (Zingerman, 2001). In Europe, Antonin Artaud, who, in fact, continued the idea of Meyerhold, wrote that the theatre should become 'not a reflection of the written text, not a physical representation of what is expressed in words but a fiery projection of all that can be extracted from a gesture, word, sound, music, and their interconnection' (Polyakov, 2000).

All this led to the attempts to return to the origins of the theatre, theatrical forms of the previous epochs (ancient plays, mystery plays, low farce, etc.). The acquaintance of the European public with the oriental theatre that was so highly valued by Meyerhold suggested the idea of synthesis of different art forms necessary for the creation of a full theatrical piece of work. Thus, we see two dominant trends in the development of a new European theatre: the idea of the necessity of studying ancient forms of the theatre and a demand for the synthesis of arts.

A. Artaud, knowing the Chinese philosophy, wrote: 'culture is a movement of the spirit that comes from the emptiness to the forms and from the forms returns to the emptiness and to the emptiness like death' (Artaud, 2000). So, getting back to the origins of the theatre meant reviving the theatre again.

\subsection{Eisenstein from theatre to cinema}

A disciple and follower of V. Meyerhold was S. Eisenstein (1898 -1948) who not only carefully studied all the changes of the new theatre but also tried to find approach to the artistic practice. The Japanese theatre tour allowed Eisenstein to combine the principles of Japanese acting with the European concepts of "expressive movement" (Ivanov, 1988). Familiarity with the Kabuki theatre had a great influence on his work.

Of similar interest for Eisenstein was the acting of a Chinese actor Mei Lan Fang (Min, Tian, 2011). The Soviet director did not miss a single performance of his. He also met him during his visits to the VGIK (Russian State University of Cinematography) (Kuleshov \& Khokhlova, 1975). Eisenstein showed particular interest in his acting since his desire was to explain art analytically as well as to develop a formula of the influence of the elements of the play on the audience. In this respect the traditions of the Chinese theatre were fruitful material for study. Eisenstein's experiments on stage, analysis of the oriental theatre tradition eventually led him to cinematography.

Transition from the theatre to the cinema of the period was a bold step for the Soviet Russia; it was revolutionary and, consequently, quite common. In those years cinema was seen as a continuation of the theatre. According to $\mathrm{N}$. Rostova the new art form only shaped the creative laws and aesthetic principles that originated in the theatre developing, going through an "aesthetic hooliganism" stage, and starting to have an impact on the theatre in turn (Rostov, 2007; Beumers, 2009).

Eisenstein began his career as a director of Moscow theatre of Proletcult (abbrev. for: Proletarian Cultural and Educational Organizations) in the early 1920s. It was in this theatre that he staged his first experimental plays. Interestingly, by that time Eisenstein had already learned Japanese. He had mastered it at the Department of Oriental Languages of the Academy of the General Staff. Therefore, his turning to the traditions of the oriental theatre as a director was quite natural. His interest in the culture of China and Japan only grew over time. In his memoirs recalling this period Eisenstein wrote: 'Thanks to this "unusual" way of thinking I was able to get a better understanding of the nature of editing' (Eisenstein, S., 1964).

Eisenstein opened new methods of film editing which he explained at the example of hieroglyphics that he learned while studying Japanese. In the article "Behind the Scenes" Eisenstein wrote about the nature of a hieroglyph and about the image of an object gradually becoming a conventional sign symbol (Eisenstein, 1998). It is necessary to point out that the hieroglyphic language did not only shape the structure of the world but also formed symbolic perception and understanding of the world. Eisenstein showed how "editing" can transfer the image of an object into concepts in hieroglyphics. For him such kind of "editing" in hieroglyphics was an analogy for editing in cinema. Eisenstein's great discovery was to edit scenes without the text but based on associative and semiotic relations. Thus, Eisenstein not only turned cinema into a synthesized art form but also introduced the principle of impact on the audience and their inclusion in the creative process. Such an impact on the feelings of the viewer was carried out via editing which was to provoke an internal monologue from the viewer. He made these discoveries while continuing studying the cultures of Japan and China. 


\subsection{Eisenstein and hieroglyph}

Chinese civilization is based on hieroglyphics. A Chinese hieroglyph is a structural cell of Chinese philosophy, the microvolume of which is equal to the whole. The Chinese language formed not only the structure of the world but also laid the symbolic understanding and perception of the world. Such perception of the world had a very close relationship with nature and at the same time hieroglyphs were not just verbal objectification of this world but also the symbols bearing a huge multi-layered meaning.

Academician V. Alekseev wrote about the relationship between the mentality of a representative of the ancient Chinese culture and special forms of creative self-expression of the Chinese. Alekseev claimed that the feature of this relationship can be expressed in the words "hieroglyphic thinking" which means an outstanding ability to shape perception of the world and at the same time to desire to focus on one thing. (Alekseev, 1958).

A painting, like any other work of art, evokes emotions. In cinema editing helps calculate the impact on the viewer and hence create certain feelings in them. A person comprehends emotions usually in the form of an internal monologue. All this was extremely important for Eisenstein because for him the inner monologue was not a method but a film structure in which he would "tone-visually record the hectic flow of thoughts" (Freilich, 1992).

The idea of the inner monologue occurred to Eisenstein when he was analyzing the Japanese and Chinese languages: 'Both of the languages have retained in the outer speech the very sensual language canon of urlogic, which, by the way, we use when we talk "to ourselves"- inner speech' (Eisenstein, 1964). These considerations of Eisenstein allow us to compare his aesthetic views on the nature of a true artist with the views of the Taoists. According to the Taoist ideas a work of art must have semantic overtones reflecting the level of spirituality of the author. From the point of view of the Taoist aesthetics an artwork should be elusive, thus the viewer is given the freedom to understand the meaning of the creation (Little \& Eichman, 2000; Kravtsova, 2004). And this, in turn, involved the perceiver into co-creation.

Hieroglyphics not only developed the way of thinking and communication but also shaped culture. As a result, the spatial framework of the work itself was determined by a hieroglyph that shaped space in which combinations of lines produced an infinite number of final forms. The space has fairly rigid boundaries including the boundaries for creativity. Games on lines are only possible within this framework. In the article "Chinese spelling" Eugene Maisel shows, at the example of the main stars of the "fifth generation" of Chinese cinematographers (Zhang Yimou and Chen Kaige), how it works and how they try to resist the "tyranny of the Hieoroglyph". If the Far Eastern civilization is doomed to eternal tyranny of the Hieroglyph, then Eisenstein was able to avoid this and to create something new for his time (Maisel, 2005).

The unity of creation and its perception is characteristic of Eisenstein's aesthetics. The idea of the hieroglyph is that it will be read and this necessarily implies the presence of a reader, a devoted reader, the one whose language is fluent, who is able to solve the puzzle of lines, dots, and emptiness. 'The desired image is not given, it appears, it is born. The image created by the author, director, and actor fixed by them in some figurative elements, again and finally sticks in the viewer's perception', considers Eisenstein (Eisenstein, S., 1998).

There were no extra or unnecessary text elements in such an understatement. In a poetic text no hieroglyph is accidental and each internal component of it adds a thought and image. In the Chinese culture a line is more important than in the European one. One line (whole or broken), i.e. trigram, both in hieroglyphics and in painting, since the "I Ching" in the Chinese cultural tradition has meant not just a line but a complex phenomenon - the beginning of creation, separation of Heaven from Earth. Painting in China is also based on a line, and some artists painted bamboo with lines. Grass-hand was more related to painting than calligraphy. Such unity of painting, poetry, calligraphy and hieroglyph has a depictive quality with its structure and system for expressing semantic relations. Interhieroglyphic relations in Chinese poetry are more based on associative fields rather than on grammar rules (parallel and cross, co-directional and opposing, etc.). For a native speaker even three - seven lines of hieroglyphs is already a poem and sometimes more than one (Gorodetskaya, 2002). As a result you get a text that cannot only be read literally but also visually and musically. This is largely due to the fact that the lyrical imagery in the art of the Far East is based on words (hieroglyphs).

The hieroglyphic system allowed to combine literature, painting, and calligraphy in the structure of a work of art. According to Sokolov-Remizov in the Far Eastern culture there is a strong relationship between art and literature: 'The lyrical and literary subtext of the images disclosed in painting, its organic and deep relation to calligraphy, and, finally, the flexibility of the poetic word led to the natural appearance of a kind of synthetic works of art where a word by means of calligraphy visibly enters the picture in the form of inscriptions' (Sokolov-Remizov, 1985). Indeed, the smooth lines of the hieroglyph, the break, the pause, the reading of a hieroglyph - all this created a unique look, a visual image of the whole work. 


\subsection{Eisenstein - hieroglyph - picture montage}

Eisenstein, who studied Far Eastern writing and knew poetry and painting, of course, tried to revise and bring into the cinema features of figurative structure of oriental culture. In this regard, film Battleship Potemkin is of particular interest (1925). Many years later in his memoirs Eisenstein would compare this film with the aesthetics of poetry and painting of China and Japan. In particular, he noted that "with great fullness the "eye music" thrives in the art of the Far East - in China and Japan. And it is particularly rich in landscape painting. The most complete examples of this can be found in China' (Eisenstein, 1964). In Battleship Potemkin there are a lot of landscape scenes dating back to the aesthetics of the Sung landscapes. However, it should be noted that Eisenstein left the majority of these scenes in black and white referring us to the Zen Buddhist aesthetic principle. Of course, it is connected with the principle of naturalness (in order to play a tree you have to become a tree). As an example is a unique experience of replacing a professional actor with a 'natural person'. So was in the films Battleship Potemkin and October - they were filmed without professional actors. This meant that Eisenstein found people who were directly involved in the events. As a result, a person did not play a role but were themselves. A viewer saw not just a film but a film-document, and they empathized, turned out to be part of these events.

In fact a Chinese or Japanese poem can be compared to a video clip in which the sound and visuals come into complex relationships resulting in a third thing called the experience. Probably, especially clearly it is manifested in the literary genre of inscriptions to the paintings - huajiang. This genre is gradually transformed in two different styles - huaba and tihuashi that were poetic themes to canvases. This is where the internal monologue is important. How deep a person can grasp the meaning of a pause (understatement), how ready he is for general understanding of a piece of art.

Thus, the scheme created by the hieroglyphic culture can be perceived not only visually but also aurally. A poem written on a beautiful scroll completed the picture and carried a special hidden meaning, which, of course, contributed to a better understanding of the beautiful scroll. This meaning is in strict sequence of a hieroglyph and a pause when the pause plays a no less semantic and rhythmic role than the hieroglyph. The scroll develops the melody of eternal and elusive: the song of the hieroglyph is replaced by a line, the pause is interrupted by a break of ink and all this drowns in the silence of a white picturesque scroll untouched with ink. Such importance of a pause and empty space again brings us back to the principle of a hint and understatement. It is also possible to note another important factor - a movement in a scroll. Such a movement of images should be read by the audience.

In the Chinese cultural tradition painting peacefully coexisted with poetry. They perfectly complemented one another. This led to the fact that poems were not limited to descriptiveness and pictures to illustrations. The poem did not only comment on a scroll but carried a special hidden meaning in the structure of the verse, which, of course, contributed to a better understanding of the beautiful scroll. This meaning is in strict sequence of a hieroglyph and a pause when the pause plays a no less semantic and rhythmic role than a hieroglyph.

Such an importance of pause and empty space can be explained by the fact that art under the influence of Zen Buddhism affirmed the principles of suggestion and understatement which involved the perceiver into co-creation. A scroll got a melody of eternal and elusive: the song of the hieroglyph is replaced by a line, a pause is interrupted by a break of ink and all this drowns in the silence of a white picturesque scroll untouched with ink. In the western art tradition we are unlikely to find empty space (neutral background) except that in the paintings of the early 20th century avant-garde.

Most consistently and deeply the technique and symbolism of hieroglyphics was transferred onto cinematic material by the Soviet director Sergei Eisenstein. Perceptual experience of a hieroglyph enriched the technique of creating an image and took Eisenstein beyond ordinary editing. This allowed him, according to V. Ivanov, to turn to the "problems of audio-visual matching in puzzling hieroglyphics' (Ivanov, 1988). Far Eastern poetry brought forth the problem of sound editing in film for Eisenstein. In his article "Vertical editing" (Eisenstein, S., 1998) the director emphasizes that the use of sound should be very careful, you cannot convert a film into the "speaking theatre". The audio-visual phenomenon poses new problems, contributes to the improvement of the methods of installation. Sound, according to S. Eisenstein, must be firmly attached to the image, intonation and movement, only then the desired effect will be achieved.

\section{Conclusion}

Thus, the director offers to maximize the concept of editing, to understand it not only as gluing pieces of film together but as the organization of the structure of a piece of work. Eisenstein notes that "any two pieces placed side by side are bound to unite into a new idea that arises from this comparison as a new quality" and adds to it the old formula "editing two strips of film is more like their product rather than a sum" since a qualitatively new content is introduced. This new 
content, created by the content of shots and the very process of their editing, attracted the attention of the researcher. The same thing happens when you create hieroglyphs: a combination of two hieroglyphs is not considered as the sum of them but as a product that reflects a complex concept. A combination of two objects or facts creates something that is difficult to present graphically. For example, an image of water and an eye means "to cry", an image of an ear and a door - "to listen", and a child and a mouth - "to shout", etc.

The analysis of the principles of hieroglyphics allowed Eisenstein to formulate the main law of film editing which became the basis of his work: "Putting together such specific details in editing brings the whole to life and forces it to occur in the perception. The whole has generated each element and connects them to one common thing namely into that generalized image in which the author, and then the viewer experience the subject".

A hieroglyph, uniting specific phenomena, objects, is able to express an abstract concept, and due to its composite nature it can incorporate a strong psychological component. For example, the hieroglyph "cry" is not just a sound produced by a person, but the sound emotionally charged that does not allow to remain indifferent to the one who hears it. Therefore, part of this hieroglyph is not an adult but a child. A similar scheme is used to create a cinematic image. Comparison of two or three parts of the material gives a complete representation of a different order - a psychological one. It is in this capacity that editing allows to express the complex inner world of characters, emotional colouring of events or phenomena, as well as the attitude of the director to this phenomenon on the screen.

A hieroglyph being created and written acquires independence, becomes a self-sufficient graphic piece of work and in that capacity enters new relationships with other characters. So is the method of installation reduced by Eisenstein to the concept of composition, structure of a film, implies dependence not just by logical connection but also by emotional bond, and so from a purely technical device goes into the category of true creativity.

Thus, both a hieroglyph and an edited video sequence form a new reality, which, like any work of art, on the one hand, is based on the reality it narrates about and, on the other hand, on the mentality and imagination of its creator. However, this reality is formed not only by the creator; the process also involves the language itself with the laws of accord and symphony, with its inner poetry and playfulness, and thus formed the linguistic reality that creates itself from within.

A film is based on a text, but the text is not implemented directly but through the vision of the director, his work with the script and composition. The task of the director is, at the editing stage, to build a sequence of shots, scenes, and organize their interaction in such a way that the viewer could see, relatively speaking, not a day in the life of a character but his whole life. To reveal the maximum depth of the plot in each minimum unit of a film was the task solved by Eisenstein, when, starting from the theatrical experience, Meyerhold's lessons, Chinese hieroglyph, he formed his theory and practice of editing. The practice that will be analyzed and implemented by many domestic and foreign filmmakers working within the framework of intellectual cinema.

\section{References}

Alekseev, V.M. (1958). In Ancient China. Moscow: Oriental Literature Arto, A. (2000). Theatre and lts Counterpart. St. Petersburg: Symposium. Berdyaev, N. (1990). Russia's Destiny: Experiments on Psychology of War and Nationality. Moscow: Thought. Beumers, B. (2009). A History of Russian Cinema (English ed.). Oxford: Berg.

Breuer, K. (2010). Japanesque: the Japanese Print in the Era of Impressionism. San Francisco: Fine Arts Museums of San Francisco. Danilevsky, N. (1991) Russia and Europe. Moscow: Book.

Eisenstein, S. (1964). Selected Works. V.1. Moscow: Art.

Eisenstein, S. (1964). Selected Works. V.3. Moscow: Art.

Eisenstein, S.M. (1998). Editing. Moscow: VGYK.

Freilich, S.I. (1992). Theory of Cinema: from Eisenstein to Tarkovsky. Moscow: Art.

Gorodetskaya, O.M. (2002). Poetic Manner of a Hieroglyph (Translator's reflections). East, 6: 5-24.

Ivanov, V.V. (1988). Eisenstein and the Cultures of Japan and China. East - West: Research. Translations. Articles, Science, $279-290$.

Kravtsova, M.E. (2004). World Art. Art History of China. St.Petersburg: Fallow Deer, Triad

Kuleshov, L. \& Khokhlova, A. (1975). 50th Anniversary of Cinema. Moscow: Art.

Little, S. \& Eichman, S. (2000). Taoism and the Arts of China. Chicago: Art Institute of Chicago.

Maisel, E. (2005). Chinese Spelling. Art of Cinema, 4: 54-61.

Polyakov, M. (2000). Theatre and Its Symbolic System. Theory of Theatre. International Agency "A.D. \& T.", 62-92.

Roshwald, A. \& Stites, R. (1999). European Culture in the Great War: the Arts, Entertainment, and Propaganda, 1914-1918. Cambridge, UK: Cambridge University Press.

Rostova, N.B. (2007). Silent Cinema and Theatre. Parallels and Crossings. History of Development and Interpenetration of Two Arts in Russia in the First Third of the 20th Century. Moscow: Aspect Press. 
Seton, M. (1952).Sergei M. Eisenstein, a Biography. New York: A.A. Wyn.

Spengler, O. (1993) The Decline of Europe. Moscow: Science.

Sokolov-Remizov, S.N. (1985). Literature - Calligraphy - Painting: the Problem of Synthesis of Arts in the Far Eastern Art. Moscow: Science.

Toynbee, A.J. (1991) A Study of History. Moscow: Progress.

Tian, M. (2012). Mei Lanfang and the Twentieth-Century International Stage: Chinese Theatre Placed and Displaced. New York: Palgrave Macmillan.

Zavadskaja, E.V. (1970). East in the West. Moscow: Science.

Zingerman, B. (2001). Introduction to the Theatre. Meyerhold V.E. Lectures: 1918-1919, 7-10. 